\title{
Effectiveness of Objectively Structured Clinical Examination in Postgraduate Training in Obstetrics and Gynecology to improve Clinical Examination Skills
}

\author{
${ }^{1}$ Neema S Acharya, ${ }^{2}$ Sourya Acharya, ${ }^{3}$ Samarth Shukla, ${ }^{4}$ Sunita Vagha
}

\section{ABSTRACT}

Aim: To determine the effectiveness of Objectively Structured Clinical Examination (OSCE) in postgraduate training in obstetrics and gynecology (OBGY) to improve clinical examination skills.

Materials and methods: Clinical examination skills of six presensitized postgraduate students were assessed though OSCE. Improvement in interpersonal and communication skills and skill of professionalism and procedural skills were assessed in successive sessions by guides using Dreyfus model. Results were analyzed by Student's t-test.

Results: There was significant improvement in interpersonal and communication skills and skill of professionalism and procedural skills.

Conclusion: Objectively Structured Clinical Examination is an effective method of evaluation for improvement in clinical examination skills of postgraduate students during their training in OBGY.

Clinical significance: Objectively Structured Clinical Examination should be used as a formative assessment method to improve skills.

Keywords: Clinical examination skills, Formative assessment, Objectively structured clinical examination.

How to cite this article: Acharya NS, Acharya S, Shukla S, Vagha S. Effectiveness of Objectively Structured Clinical Examination in Postgraduate Training in Obstetrics and Gynecology to improve Clinical Examination Skills. J South Asian Feder Menopause Soc 2018;6(1):8-12.

Source of support: Nil

Conflict of interest: None

Date of received: 10 January 2018

Date of acceptance: 27 January 2018

Date of publication: August 2018

\footnotetext{
${ }^{1-4}$ Professor

${ }^{1}$ Department of Obstetrics and Gynecology, Datta Meghe Institute of Medical Sciences, Wardha, Maharashtra, India

${ }^{2}$ Department of Medicine, Datta Meghe Institute of Medical Sciences, Wardha, Maharashtra, India

${ }^{3,4}$ Department of Pathology, Datta Meghe Institute of Medical Sciences, Wardha, Maharashtra, India

Corresponding Author: Neema S Acharya, Professor Department of Obstetrics and Gynecology, Datta Meghe Institute of Medical Sciences, Wardha, Maharashtra, India e-mail: neemadk@hotmail.com
}

\section{INTRODUCTION}

Physical examination skills have been traditionally viewed among the most valuable skills taught during medical education, ${ }^{1-3}$ contributing to more cost-effective use of diagnostic services, while rewarding physicians with the excitement and satisfaction of making a diagnosis using their knowledge and skills. ${ }^{1,2}$ These skills also increase direct contact with patients, and the therapeutic value of the human touch is impossible to quantify. $^{2}$

Several investigators have reported an overall decline in clinical skills of medical students and residents with residents less well prepared for taking an adequate medical history, performing a reliable physical examination, and effectively communicating with patients while relying on ordering tests without always knowing how to interpret them. ${ }^{1}$ In an era of increasing health care costs, we need to reconsider the importance of physical examination skills. ${ }^{1,2}$

Despite documented deficiencies in clinical skills, medical school and residency curricula do not emphasize clinical skills teaching or assessment. ${ }^{3}$ Reported barriers to teaching clinical examination skills include a scarcity of good teaching patients, lack of time for teaching at the bedside, an overreliance on technology, and a shortage of skilled faculty to impart this knowledge. Clinical skills can be developed through standard teaching methods or evaluation methods like OSCE where the student had to perform and get rating of his performance and thereby can improve in future.

An OSCE is a modern ${ }^{1}$ type of examination often used in health sciences. It is designed to test clinical skill performance and competence in skills, such as communication, clinical examination, medical procedures/prescription, exercise prescription, joint mobilization/manipulation techniques, radiographic positioning, radiographic image evaluation, and interpretation of results.

An OSCE usually comprises a circuit of short (the usual is $5-10$ minutes although some use up to 15 minutes) stations, in which each candidate is examined on a oneto-one basis with one or two impartial examiner(s) and either real or simulated patients (actors). Each station has a different examiner, as opposed to the traditional 
method of clinical examinations where a candidate would be assigned to an examiner for the entire examination. Candidates rotate through the stations, completing all the stations on their circuit. In this way, all candidates take the same stations. It is considered to be an improvement over traditional examination methods because the stations can be standardized enabling fairer peer comparison, and complex procedures can be assessed without endangering patient's health. $^{2}$

As the name suggests, an OSCE is designed to be

- Objective: All candidates are assessed using exactly the same stations (although if real patients are used, their signs may vary slightly) with the same marking scheme. In an OSCE, candidates get marks for each step on the mark scheme that they perform correctly, which therefore makes the assessment of clinical skills more objective, rather than subjective, which is where the examiners decide whether or not the candidate fails based on their subjective assessment of their skills.

- Structured: Stations in OSCEs have a very specific task where simulated patients are used, detailed scripts are provided to ensure that the information that they give is the same to all candidates, including the emotions that the patient should use during the consultation. Instructions are carefully written to ensure that the candidate is given a very specific task to complete. The OSCE is carefully structured to include parts from all elements of the curriculum as well as a wide range of skills.

- Clinical examination: OSCE is designed to apply clinical and theoretical knowledge. Where theoretical knowledge is required, e.g., answering questions from the examiner at the end of the station, then the questions are standardized and the candidate is only asked questions that are on the mark sheet and if they are asked any others, then there will be no marks for them.

- Objectively structured clinical examination marking: Writing a prescription chart, and these are marked like written examinations, again usually using a standardized mark sheet. One of the ways an OSCE is made objective is by having a detailed mark scheme and standard set of questions.

\section{Aim}

Aim of the present study is to study the effectiveness of OSCE in postgraduate training in obstetrics and gynecology to improve skills in clinical examination of antenatal patient.

\section{Objectives}

- To study the effectiveness of OSCE to improve clinical examination skills of postgraduate students.
- To know the feasibility to conduct OSCE as formative assessment method for postgraduate students of Datta Meghe Institute of Medical Sciences (DMIMSU).

\section{MATERIALS AND METHODS}

The study was carried out in the Department of Obstetrics and Gynecology, DMIMSU, under the guidance of the Department of Medical Education from March 2013 to June 2013. As a pilot study, six second year postgraduate students (as OSCE examinee) and six postgraduate guides (as OSCE observers) of the Department of Obstetrics and Gynecology, DMIMSU, Wardha, were presensitized and participated in the study. Study was approved by the Ethical Committee of the institute.

\section{Methods}

The level of clinical examination skills of examinees was assessed through feedback given by the observers along the Dreyfus Model of Skill Acquisition Model questionnaire before the OSCE sessions.

A presensitization session on OSCE and the project was done for the examinees and the observers separately. During sensitization the examinees were explained in detail about what is OSCE and the details of stations.

The observers were explained regarding OSCE, role of observers, and details of stations.

\section{Preparation of Stations}

Since the aim of this study was to improve clinical examination skills of examinee in examination of antenatal patients, the task was the same at every station to do clinical examination of antenatal patients with different clinical diagnosis placed in six stations. All students were rotated and went through all stations.

The clinical scenarios were same in every OSCE station. They were real clinically diagnosed cases of anemia, preeclampsia, with history of previous cesarean section, malpresentation, oligohydramnios, and intrauterine growth rate.

The scoring sheet was prepared as per the OSCE norms using skill assessment scale of Dreyfus and Dreyfus ${ }^{4}$ model, with lowest score of 1 and highest being 5 .

Three aspects were assessed in detail:

- Interpersonal and communication skills

- Skill of professionalism

- Procedural skill

\section{Selection of Observers}

The teachers who are eligible as postgraduate guides for students of the Department of Obstetrics and Gynecology were appointed as observers. They all gave consent to participate in this project. 
A feedback was taken at the end of OSCE on the observer's opinion on OSCE as formative assessment for improving clinical examination skills of postgraduate students. A total of six OSCE sessions were conducted weekly for 2 months in the Department of Obstetrics and Gynecology, Acharya Vinoba Bhave Rural Hospital, Wardha, in March and April 2013 on different selected scenarios. Standardized evaluation was done by the selected observers. Post program feedback was taken as per pretest format, from both the observers and the examinees.

Primary outcome - the improvement in clinical examination skill assessed by Dreyfus scale.

Secondary outcome - the feasibility of carrying OSCE as formative assessment method (through feedback).

\section{Statistical Analysis}

The results were analyzed by valid statistical methods. It was done using Student's t-test and level of significance will be considered as p-value $<0.05$.

\section{OBSERVATION AND RESULTS}

Number of examinees was 6 (A, B, C, D, E, F) Junior Residents 2 of the Department of Obstetrics and Gynecology, DMIMSU. Number of observers (postgraduate guides) was 6 .

A total of six OSCE sessions were conducted. Each session has six stations with mentioned clinical diagnosis with same task, i.e., clinical examination. The following charts depict the improvement in the skill of clinical examination pre- and post-OSCE sessions as per the Dreyfus Model of Skill Acquisition.

\section{Paired t-test Results}

p-value and statistical significance: The two-tailed p-value $=0.0039$.



Graph 1: Improvement in score in interpersonal and communication skill
By conventional criteria, this difference is considered to be very statistically significant.

Confidence interval: The mean of Group 1 minus Group $2=-2.40$.

95\% confidence interval of this difference is from -3.51 to -1.29 .

\section{Paired t-test Results}

p-value and statistical significance: The two-tailed p-value $=0.0026$.

By conventional criteria, this difference is considered to be very statistically significant.

Confidence interval: the mean of Group 1 minus Group $2=-3.00$.

$95 \%$ confidence interval of this difference is from -4.24 to -1.7 .

\section{DISCUSSION}

As seen in the result charts, students have shown significant improvement in all three aspects of clinical examination skills.

- Graph 1 shows there is remarkable improvement in interpersonal and communication skill with postOSCE score improvement ( $\mathrm{p}$-value $=0.0007$ ).

- Graph 2 shows post-OSCE improvement in professionalism $(p$-value $=0.0039)$.

- Graph 3 shows improvement in actual procedural skill after OSCE sessions $(\mathrm{p}$-value $=0.0026)$. These results are similar and comparable with studies done by Sloan et $\mathrm{al}^{5}$ and Harden and Gleeson. ${ }^{6}$

As seen in studies done by Brown et $\mathrm{al}^{7}$ and Ram et al, ${ }^{8}$ both the students and the observers were happy with the concept of OSCE as a method of formative assessment in postgraduate curriculum. The postgraduate students felt that it was a realistic assessment for the course (clinical

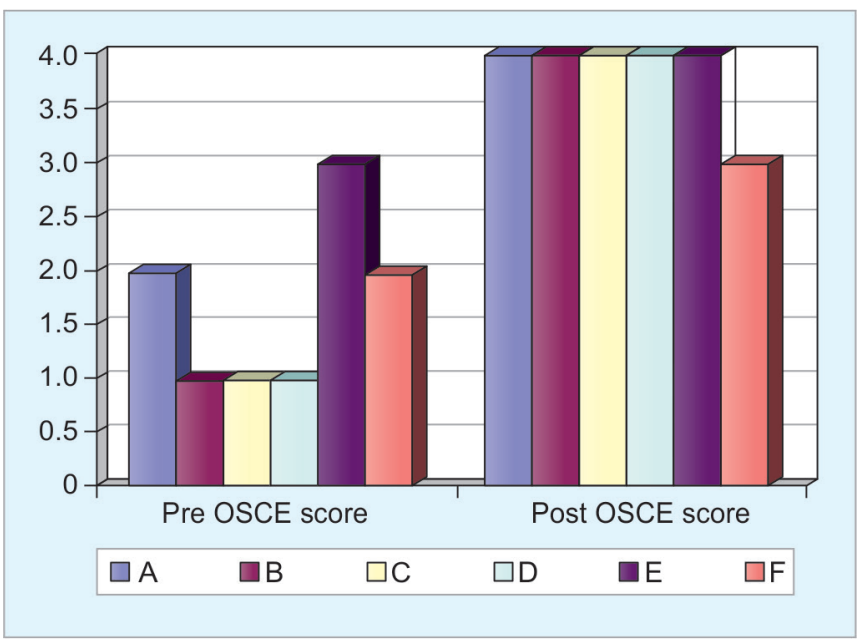

Graph 2: Improvement in professionalism 


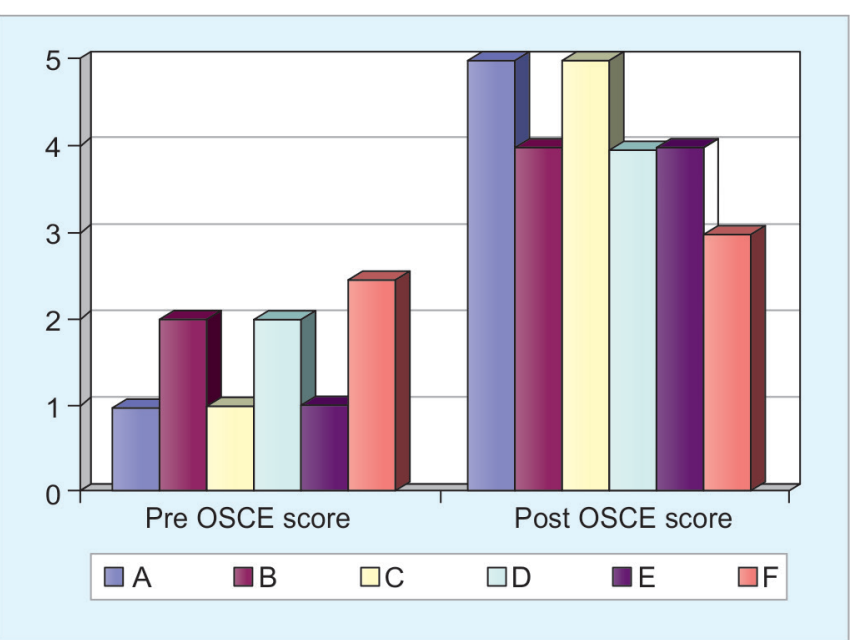

Graph 3: Improvement in procedural skill

examination skills). It could assess all aspects of clinical examination skills. The task was well defined. The time for each station was adequate. It was not stressful than the standard assessment methods. Students agreed that it could assess their ability on problem-solving and level of clinical examination skills. Observation scoring sheet makes it a nonbiased and uniform method of assessment. It motivated me for further learning.

The observers also agreed with almost all points mentioned earlier except that they felt that the (examiner) observer was not actively involved at the time of examination and could not intervene to help the student in case of need.

In this study students evaluated the experience positively and perceived the faculty time.

In this study the stations were kept with same patient's diagnosis and same task of clinical examination, making it a modified OSCE as per the need of this project. The modified OSCE provides another approach to the assessment of clinical performance as per the need of type of skill assessment.

\section{PRACTICAL CONSIDERATIONS AND POTENTIAL BARRIERS}

These included recruitment, training, and retention of a large volume of real patients (or Simulated Patients), time and training for faculty observers, test development costs in both time and expertise, and maintenance of usable clinical space to administer the test.

\section{BENEFITS}

Despite such potential barriers and questions about the psychometric properties of OSCEs, recent reports have highlighted the often hidden benefits of long-term, comprehensive OSCEs. For example, educators subjec- tively believe in high-fidelity assessment, and students and educators generally feel positive about this type of performance testing. Beyond this subjective experience, Duerson et al reported significant student, curricular, and faculty development outcomes after 9 years of OSCE testing. Student performance improved, small-group teaching sessions were standardized, and faculty received feedback that improved instruction and enthusiasm for teaching physical examination skills com-mitment as an expression of faculty interest in teaching. ${ }^{9}$ Moreover, after passing the OSCE, student confidence increased, and anxiety about upcoming clinical rotations decreased.

\section{CONCLUSION}

Medical education is a public trust. Indeed, medical educators have always needed the best methods for formative and summative evaluation of trainees. The renewed emphasis on patient safety and quality outcomes in social consciousness and payer system necessitates that medical educators use high-quality, reliable, valid, educationally sound assessment methods. Moreover, OSCE as formative assessment provides many opportunities for assessment and learning that other traditional evaluation methods also do not afford. The benefits of OSCE method to learners, faculty, institutions, and the public at large are great.

Successful OSCEs are often the result of significant planning, coordination of multiple resources, commitment to large-scale testing, and judicious use of assessment data.

More research is needed about the best uses of the OSCE method. Advocates of the OSCE method should continue to produce and disseminate evidence of the far-reaching impact that is seen by students and educators. All institutions should avoid the overreliance on any single evaluation method and judge the relative value of comprehensive testing of future professional practice.

\section{REFERENCES}

1. Bordage G. Where are the history and the physical? CMAJ 1995 May;152(10):1595-1598.

2. Mangione S, Peitzman SJ. Physical diagnosis in the 1990s: art of artifact? J Gen Intern Med 1996 Aug;11(8):490-493.

3. Kern DC, Parrino TA, Korst DR. The lasting value of clinical skills. JAMA 1985 Jul;254(1):70-76.

4. Dreyfus, SE.; Dreyfus, HL. A five-stage model of the mental activities involved in directed skill acquisition. Washington (DC): Storming Media; 1980.

5. Sloan DA, Donnelly MB, Schwartz RW, Strodel WE. The objective structured clinical examination. The new gold standard for evaluating postgraduate clinical performance. Ann Surg 1995 Dec;222(6):735-742. 
6. Harden RM, Gleeson FA. Assessment of clinical competence using an objective structured clinical examination (OSCE). Med Educ 1979 Jan;13(1):41-54.

7. Brown, B.; Roberts, J.; Rankin, J.; Stevens, B.; Tompins, C.; Patton, D. The objective structured clinical examination: reliability and validity. In: Hart IR, Walton HJ, editors. Further developments in assessing clinical competence. Montreal: Canadian Health Publications; 1987. pp. 563-571.
8. Ram P, van der Vleuten C, Rethans JJ, Schouten B, Homba S, Grol R. Assessment in general practice: the predictive value of written knowledge tests and a multiple-station examination for actual medical performance in daily practice. Med Educ 1999 Mar;33(3):197-203.

9. Davidson RA, Duerson M, Romrell L, Pauly R, Watson RT. Evaluating evidence-based medicine skills during a performance-based examination. Acad Med 2004 Mar;79(3):272-275. 